\title{
Continuous hemofiltration improves the prognosis of bacterial sepsis complicated by liver dysfunction in children
}

\author{
Yun Cui ${ }^{1,2+}$, Xi Xiong ${ }^{1,2+}$, Fei Wang ${ }^{1,2}$, Yuqian Ren ${ }^{1,2}$, Chunxia Wang ${ }^{1,2^{*}}$ and Yucai Zhang ${ }^{1,2^{*}}$ (D)
}

\begin{abstract}
Background: Liver dysfunction is an independent risk factor for poor prognosis of patients with sepsis. The aim of this study is to evaluate the effects of continuous hemofiltration in patients with bacterial sepsis complicated by liver dysfunction.

Methods: We retrospectively analyzed the medical records of 27 cases of bacterial sepsis with liver dysfunction admitted to pediatric intensive care unit (PICU) of Shanghai Children's Hospital between January 2013 and December 2016.

Results: 28-day mortality and length of PICU stay were significantly reduced in the continuous hemofiltration group $(n=16)$ compared with the conventional management group $(n=11)(31.3 \%$ vs. $72.7 \%, 9$ [4-23] vs. 14 [4-36], respectively, both $P<0.05)$. The interval time between PICU admission and continuous hemofiltration initiation was (22.06 \pm 17.68$) \mathrm{h}$, and the median time of continuous hemofiltration duration was $48 \mathrm{~h}(31-70 \mathrm{~h})$. After $72 \mathrm{~h}$ hemofiltration, the levels of total bilirubin (TBIL), direct bilirubin (DBIL), total bile acids (TBA), ammonia, lactate (Lac), TNF-a and IL-6 were significantly decreased in the continuous hemofiltration group. Moreover, multivariate logistic regression analysis indicated that continuous hemofiltration treatment and the TBIL level were independently associated with 28-day mortality of patients with bacterial sepsis complicated by liver dysfunction.
\end{abstract}

Conclusions: Continuous hemofiltration significantly decreases the serum levels of TBIL, DBIL, TBA, Lac, ammonia, TNF- $a$, IL-6, and improves 28-day mortality of patients with bacterial sepsis complicated by liver dysfunction.

Keywords: Continuous hemofiltration, Bacterial sepsis with liver dysfunction, Mortality, Children

\section{Background}

Sepsis is defined as life-threatening organ dysfunction caused by a deregulated host response to infection [1]. Until now, bacteria is still the most common pathogens of sepsis [2]. Specifically, Gram-negative (G-) bacteria are among the most important pathogens of sepsis, and lipopolysaccharide (LPS) is regarded as an important stimulator of triggering the systemic inflammatory reaction [3]. The amount of proinflammatory cytokines including tumor necrosis factor (TNF)- $\alpha$ and interleukin (IL)- 6 contribute to liver dysfunction [4]. In addition, the stimulated liver produces and releases high amounts of bioactive lipids and acute phase

\footnotetext{
*Correspondence: karencx0465@163.com; zyucai2018@163.com

${ }^{\dagger}$ Yun Cui and Xi Xiong contributed equally to this work.

'Department of Critical Care Medicine, Shanghai Children's Hospital,

Shanghai Jiao Tong University, No.355 Luding Road, Putuo District, Shanghai

200062, China

Full list of author information is available at the end of the article
}

proteins [5], which also play an important role in sepsis-induced liver dysfunction [6]. Liver dysfunction is an independent risk factor for a poor prognosis of patients with sepsis, and the mortality of sepsis-associated liver dysfunction is $54.3-67.6 \%[7,8]$. The bacterial sepsis complicated by liver dysfunction in children remains the leading causes of death in pediatric intensive care unit (PICU).

Continuous renal replacement treatment (CRRT) preferred as adjuvant therapy in critically ill patients to improve hemodynamics and fluid balance and remove noxious molecules and cytokines [9-11]. Recently, a retrospective cohort study indicated that continuous hemofiltration provides stability and bridge to liver transplantation in patients with pediatric acute liver failure [12]. However, there is little study available about the continuous hemofiltration in sepsis complicated by liver dysfunction, especially initially infected by bacteria in children. In the present 
study, we retrospectively analyzed the medical records of patients with bacterial sepsis complicated by liver dysfunction admitted to PICU at Shanghai Children's Hospital from January 2013 to December 2016. The aim of the study was to evaluate the effects of continuous hemofiltration on 28-day mortality and the levels of total bilirubin (TBIL), direct bilirubin (DBIL), total bile acids (TBA), lactate (Lac), ammonia, TNF- $\alpha$ and IL- 6 in patients with bacterial sepsis complicated by liver dysfunction.

\section{Methods}

\section{Study design}

We performed a retrospective observational study of patients with bacteria sepsis-associated liver dysfunction admitted to PICU at Shanghai Children's Hospital between January 2013 and December 2016. The study was conducted in accordance with the ethical principles of the Declaration of Helsinki (and subsequent revisions) and to the current norm for observational studies. This study was approved by the Ethics Committee of Shanghai Children's Hospital (No. 2016R010-E02). The written informed consents were obtained from all patients' parents.

\section{Patients and treatment}

Patients more than 1 month and under 14 years old who were diagnosed with sepsis-associated liver dysfunction initially infected by bacteria were screened for inclusion. The patient was diagnosed with sepsis based on the International Pediatric Sepsis consensus conference in 2005 [13] and "Surviving Sepsis Campaign" international guidelines in 2012 [14]. Liver dysfunction is defined as plasma TBIL above $4 \mathrm{mg} / \mathrm{dl}$ or $70 \mu \mathrm{mol} / \mathrm{L}$ according to Surviving Sepsis Campaign International Guidelines in 2012 [14]. And patients initially infected by bacteria were confirmed by laboratory finding. Patients discharged $72 \mathrm{~h}$ earlier after admission were excluded. And patients with primary hepatobiliary diseases or inherited metabolic diseases were excluded. Primary hepatobiliary involvement was defined as liver trauma, hepatitis, malignancy, and cholecystitis. All patients were treated with conventional management according to "Surviving Sepsis Campaign" international guidelines in 2012 [14]. All the patients' parents signed the informed consents before continuous hemofilatration treatment if the patients received continuous hemofiltration.

\section{Continuous hemofiltration}

The pattern of CRRT used in patients with bacterial sepsis complicated by liver dysfunction was continuous hemofiltration performed using PRISMA or PRISMA flex blood purification machine and Gambro prisma filter with an ultrafiltrate flow rate of $35-50 \mathrm{~mL} / \mathrm{kg} / \mathrm{hr}$. The indications for initiation of continuous hemofiltration included acute kidney injury, fluid overload ( $>10 \%)$, or hyperammonemia ( $>100 \mu \mathrm{mol} / \mathrm{L}$ ) as described in our previous study [15], as well as hemodynamic instability such as cardiogenic shock, septic shock and multiple organ dysfunction $[16,17]$. The patients with severe coagulation disorders (APTT $>80 \mathrm{~s}$ or INR > 2.5), or with biofilm allergic reaction, or with difficult to set venin catheter-access were treated with conventional therapies. According to patient body weight, we chose a $6 \mathrm{~F}$ to $12 \mathrm{~F}$ central venous catheters (GamCath; Gambro, Colombes, France) to construct the vascular access in the right internal jugular or femoral vein. Continuous hemofiltration was performed as described in our previous study [15]. Briefly, the saline containing 5000-10,000 IU/L heparin was used to pre-treat the filter circuit. And the dosage of heparin was 5-20 U/kg.h to maintain activated partial thromboplastin time (APTT) with 1.5-2 fold of normality during continuous hemofiltration. The replacement solution contains $\mathrm{Na}^{+} 130 \mathrm{mmol} / \mathrm{L}, \mathrm{K}^{+} 4 \mathrm{mmol} / \mathrm{L}, \mathrm{HCO}^{3-}$ $28 \mathrm{mmol} / \mathrm{L}, \mathrm{Ca}^{2+} 1.5 \mathrm{mmol} / \mathrm{L}, \mathrm{Mg}^{2+} 3.2 \mathrm{mmol} / \mathrm{L}, \mathrm{Cl}^{-}$ $109 \mathrm{mmol} / \mathrm{L}$, and glucose $3.7 \mathrm{~g} / \mathrm{L}$. The blood flow rate was set as $4-6 \mathrm{~mL} / \mathrm{kg} / \mathrm{min}$, and the hemofilter was changed for about $24 \mathrm{~h}$ or when clotted. When the urine output is over $1 \mathrm{ml} / \mathrm{kg} . \mathrm{h}$, fluid overload below $10 \%$, the level of TBIL less than $85 \mu \mathrm{mol} / \mathrm{L}$ or hemodynamics keeping stable, continuous hemofiltration was weaned. Otherwise, continuous hemofiltration should be terminated when children develop severe bleeding or are unable to control acute hemorrhage; or clinical symptoms are not obviously improved after $48 \mathrm{~h}$ of treatment.

\section{Observational data}

The demographic data were collected from medical records. The 28-day mortality and the changes of serum levels of biochemical and clinical parameters including alanine aminotransferase (ALT), $\gamma$-glutamyltranspeptidase $(\gamma$-GT), TBIL, DBIL, TBA, lactate (Lac), ammonia, TNF- $\alpha$ and IL-6, prothrombin time (PT), activated partial thromboplastin time (APTT) and international normalized ratio (INR) were analyzed.

\section{Statistical analysis}

Data were analyzed using SPSS (v.22.0) (SPSS Inc., Chicago, IL). Continuous variables were summarized as means \pm standard derivations (SD) for normal distribution data and as median (range) for abnormal distribution data. All variables were tested for normal distribution by using the Kolmogorov-Smirnov test. Partial were transferred to normal distribution by the $L n$ treatment. Student $t$ test was used to compare the means of continuous variables and normally distributed data; otherwise, the Mann-Whitney $U$ test was used. The chi-square test was used to compare the categorical data. The independent factors correlated with 28-day mortality were assessed by applying 
multivariate logistic regression analysis and Spearman's rank correlation coefficient. A value of $P<0.05$ was considered statistically significant.

\section{Results}

A total of 80 children diagnosed with sepsis-associated liver dysfunction were admitted to the PICU at Shanghai Children's Hospital between January 2013 and December 2016. One patient was excluded due to unknown cause. Sixteen patients were excluded due to primary hepatobiliary disease, inherited metabolic diseases and drug intoxication. Thirty-seven patients were excluded due to viral infection, fungal infection or diverse infection. Finally, 27 patients with sepsis-associated liver dysfunction initially infected by bacteria met inclusion criteria, which included 13 male children and 14 female children. And 11 patients received conventional management, and 16 cases were treated with conventional management plus continuous hemofiltration as adjuvant therapy according to medical records (Fig. 1). And the pathogens include Escherichia coli (10/27), Pseudomonas aeruginosa (6/27), Klebsiella pneumonia (1/27), Streptococcus pneumonia (7/27) and Staphylococcus aureus (3/27). Fourteen patients survived, and 13 patients died. The demographic and clinical characteristics of patients were detailed in Table 1.

\section{Demographic and clinical characteristics}

The characteristics of patients in the conventional management group and the continuous hemofiltration group were similar in respect of age, gender, Pediatric Risk of Mortality III (PRISM III), fever, complications, rate of hepatomegaly or hypoproteinemia, infection origin, pathogens, infection biomarkers and liver function (all $P>0.05$ ). The length of PICU stay was significantly shorter in patients of continuous hemofiltration group compared with the conventional management group (9 [4-23] vs. 14 [4-36], $P<0.05)$. And 28-day mortality was significantly reduced in patients of continuous hemofiltration group compared with the conventional management group (31.3\% vs. $72.7 \%, P<0.05$, Table 1 ).

\section{Clinical benefits of continuous hemofiltration in patients with sepsis-associated liver dysfunction}

The median interval time between continuous hemofiltration initiation and PICU admission was (22.06 \pm 17.68) h. Moreover, the median interval time in non-survivor was significantly longer than that in survivor $(37.40 \pm 25.53$ vs. $15.09 \pm 6.09, P<0.05)$. The median time of continuous hemofiltration duration was $48 \mathrm{~h}(31-70 \mathrm{~h})$ in patients with sepsis-associated liver dysfunction. The 28-day mortality rate in continuous hemofiltration group was $31.3 \%$ (5/16), which was significantly decreased compared with the conventional therapy group $(72.7 \%, 8 / 11)$. The levels of TBIL, DBIL, TBA, Lac, TNF- $\alpha$ and IL- 6 were significantly decreased at $72 \mathrm{~h}$ after treatment in the continuous hemofiltration group (all $P<0.05$ ), other than in the conventional group (all $P>0.05$, Table 2). The serum levels of TNF- $\alpha$ and

Sepsis-associated liver dysfunction enrolled $(n=80)$

(1) met the criteria of sepsis

(2) no history of chronic liver diseases

(3) plasma total bilirubin above $4 \mathrm{mg} / \mathrm{dL}$ or $70 \mu \mathrm{mol} / \mathrm{L}$

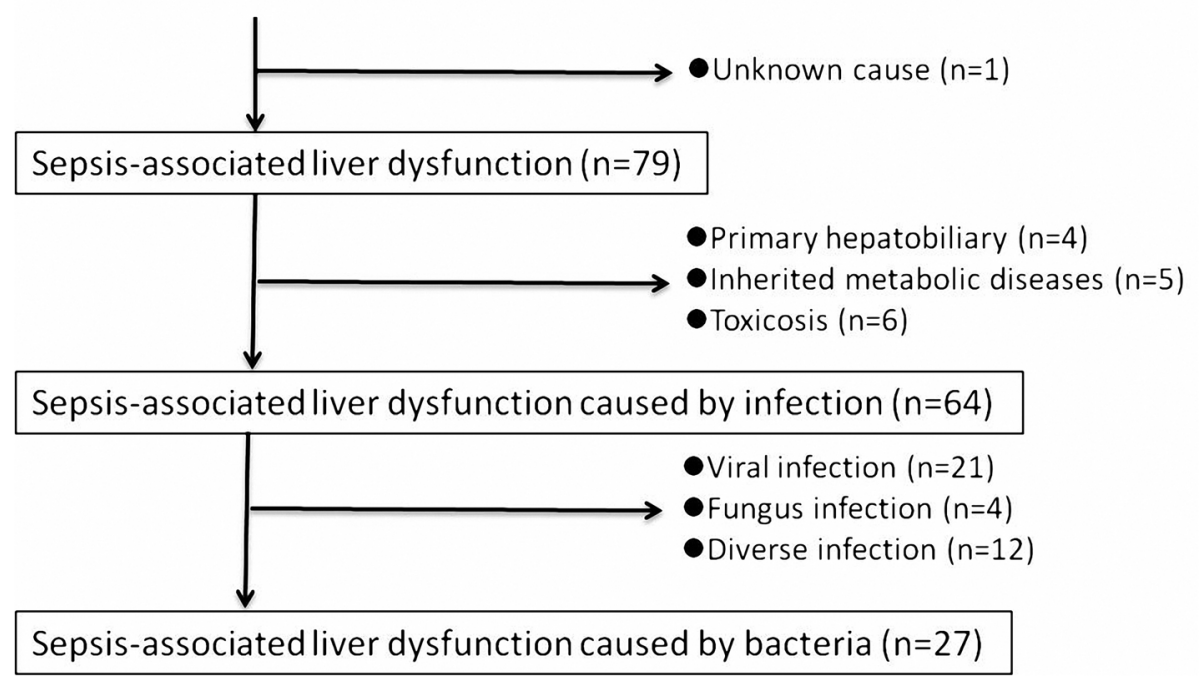

Fig. 1 Flowchart of patient enrollment in this study 
Table 1 Demographic and clinical characteristics of patients with sepsis complicated by liver dysfunction enrolled in this study

\begin{tabular}{|c|c|c|c|}
\hline Demographic and Clinical Characteristics & Conventional group $(n=11)$ & Continuous hemofiltration group $(n=16)$ & $P$ \\
\hline Age, month, median (range) & $12(2-192)$ & $54(3-144)$ & 0.239 \\
\hline Male, n (\%) & $6(54.5 \%)$ & $7(43.7 \%)$ & 0.581 \\
\hline Stay in PICU, day, median (range) & $14(4-36)$ & $9(4-23)$ & $0.022^{*}$ \\
\hline Body temperature, ${ }^{\circ} \mathrm{C}$ & $38.3(36.0-40.0)$ & $39(38.0-41.0)$ & 0.080 \\
\hline Hepatomegaly, n (\%) & $6(54.5 \%)$ & $10(62.5 \%)$ & 0.679 \\
\hline Hypoproteinemia, n (\%) & $9(81.8 \%)$ & $13(81.3 \%)$ & 0.970 \\
\hline $\begin{array}{l}\text { Pediatric Risk of Mortality III } \\
\text { (PRISM III), median (range) }\end{array}$ & 13(10-18) & $14(10-20)$ & 0.427 \\
\hline \multicolumn{4}{|l|}{ Co-organ dysfunction } \\
\hline ARDS, n (\%) & $5(45.4 \%)$ & $8(50 \%)$ & 0.816 \\
\hline Kidney injury, n (\%) & $4(36.4 \%)$ & $7(43.7 \%)$ & 0.701 \\
\hline Encephalopathy, n (\%) & $2(18.2 \%)$ & $8(50 \%)$ & 0.202 \\
\hline Shock, n (\%) & $5(45.4 \%)$ & $8(50.0 \%)$ & 0.816 \\
\hline \multicolumn{4}{|l|}{ Infection origin } \\
\hline Respiratory system, n (\%) & $5(45.4 \%)$ & $6(37.5 \%)$ & 0.679 \\
\hline Digestive system, n (\%) & $3(27.3 \%)$ & $4(25.0 \%)$ & 0.895 \\
\hline Urinary system, n (\%) & $1(9.1 \%)$ & $2(12.5 \%)$ & 0.780 \\
\hline Central nervous system, n (\%) & $2(18.2 \%)$ & $4(25.0 \%)$ & 0.673 \\
\hline \multicolumn{4}{|l|}{ Pathogens } \\
\hline Escherichia coli, n & $4(9.1 \%)$ & $6(37.65 \%)$ & 0.952 \\
\hline Pseudomonas aeruginosa, $\mathrm{n}$ & $3(27.3 \%)$ & $3(18.8 \%)$ & 0.603 \\
\hline Klebsiellapneumoniae, $\mathrm{n}$ & $0(0 \%)$ & $1(6.3 \%)$ & 1.000 \\
\hline Streptococcus pneumoniae, $\mathrm{n}$ & $3(27.3 \%)$ & $4(25.0 \%)$ & 0.895 \\
\hline Staphylococcus aureus, n & $1(9.1 \%)$ & $2(12.5 \%)$ & 0.780 \\
\hline \multicolumn{4}{|l|}{ Infection markers } \\
\hline WBC & $11.85 \pm 6.90$ & $12.10 \pm 8.07$ & 0.933 \\
\hline PCT & $5.21 \pm 4.29$ & $6.39 \pm 4.28$ & 0.489 \\
\hline CRP & $98.09 \pm 55.29$ & $98.25 \pm 53.47$ & 0.994 \\
\hline \multicolumn{4}{|l|}{ Liver function } \\
\hline PT & $24.60 \pm 22.70$ & $26.78 \pm 17.01$ & 0.778 \\
\hline $\mathrm{ALT}$ & $548.20 \pm 264.14$ & $570.00 \pm 229.97$ & 0.822 \\
\hline TBIL & $176.74 \pm 81.01$ & $185.52 \pm 142.48$ & 0.855 \\
\hline DBIL & $133.34 \pm 62.75$ & $141.73 \pm 103.95$ & 0.813 \\
\hline 28-day mortality, n (\%) & $8(72.7 \%)$ & $5(31.3 \%)$ & $0.034^{*}$ \\
\hline
\end{tabular}

ARDS acute respiratory distress syndrome, MODS multiple organ dysfunction syndrome, WBC white blood cell, $\times 10^{9} / \mathrm{L}, P C T$ procalcitonin, $\mathrm{ng} / \mathrm{mL}, C R P C$-reactive protein, $\mathrm{mg} / \mathrm{L}, P T$ prothrombin time, $\mathrm{s}, A L T$ alanine transaminase, $\mathrm{U} / \mathrm{L}, T B I L$ total bilirubin, $\mu \mathrm{mol} / \mathrm{L}, D B / L$ direct bilirubin, $\mu \mathrm{mol} / \mathrm{L}$

* indicates $P<0.05$ compared with conventional group

IL-6 decreased about $30-40 \%$ in patients treated with continuous hemofiltration during the first $72 \mathrm{~h}$ after admission, but not in the conventional group (Fig. 2).

Independent factors for 28-day mortality of patients with sepsis-associated liver dysfunction

The clinical characteristics of patients with bacterial sepsis-associated liver dysfunction admitted to PICU were compared between survivors and non-survivors. In the present study, the characteristics of survivors and non-survivors were similar with respect to gender, PRISM III score, fever, complications, rate of hepatomegaly or hypoproteinemia, infection origin, infection markers (all $P>0.05$ ) (Table 3 ). And there was no significant difference about 28-day mortality among difference bacterial aetiology (all $P>0.05$ ), and there was no significant difference in respect of age (30 [2-132] months vs. 12 [2-192] months, $P=0.704$ ) (Table 3). The 
Table 2 Changes of the serum levels of biomarkers in patients with sepsis-associated liver dysfunction initially infected by bacteria after treatment with or without continuous hemofiltration

\begin{tabular}{|c|c|c|c|c|c|c|}
\hline \multirow[t]{2}{*}{ Variables } & \multicolumn{3}{|c|}{ Conventional group $(n=11)$} & \multicolumn{3}{|c|}{ Continuous hemofiltration group $(n=16)$} \\
\hline & T0 & $\mathrm{T} 72$ & $P$ & T0 & T72 & $P$ \\
\hline ALT & $548.20 \pm 264.14$ & $427.55 \pm 241.37$ & 0.277 & $570.00 \pm 229.97$ & $418.81 \pm 205.74$ & 0.059 \\
\hline AST & $1011.11 \pm 639.04$ & $721.09 \pm 330.22$ & 0.196 & $1007.81 \pm 833.87$ & $611.81 \pm 597.51$ & 0.133 \\
\hline$\gamma-\mathrm{GT}$ & $185.45 \pm 152.1$ & $160.91 \pm 126.62$ & 0.685 & $165.06 \pm 83.58$ & $168.15 \pm 71.53$ & 0.911 \\
\hline TBIL & $176.74 \pm 81.01$ & $132.87 \pm 75.72$ & 0.204 & $185.52 \pm 142.48$ & $62.59 \pm 59.60$ & $0.003^{*}$ \\
\hline DBIL & $133.34 \pm 62.75$ & $99.07 \pm 43.66$ & 0.153 & $141.73 \pm 103.96$ & $49.05 \pm 25.65$ & $0.002^{*}$ \\
\hline TBA & $97.31 \pm 33.32$ & $93.95 \pm 49.00$ & 0.853 & $104.73 \pm 24.57$ & $78.40 \pm 17.54$ & $0.002^{*}$ \\
\hline ALP & $183.27 \pm 20.18$ & $175.00 \pm 42.37$ & 0.565 & $159.56 \pm 36.35$ & $137.25 \pm 59.23$ & 0.209 \\
\hline PT & $24.60 \pm 22.70$ & $13.53 \pm 3.29$ & 0.125 & $26.78 \pm 17.01$ & $14.29 \pm 5.89$ & $0.009^{*}$ \\
\hline APTT & $61.56 \pm 19.75$ & $53.25 \pm 18.04$ & 0.315 & $63.15 \pm 33.76$ & $51.38 \pm 22.75$ & 0.256 \\
\hline INR & $1.61 \pm 0.82$ & $1.48 \pm 0.30$ & 0.631 & $2.20 \pm 1.69$ & $1.43 \pm 0.36$ & 0.084 \\
\hline Fib & $1.57 \pm 0.92$ & $2.05 \pm 0.70$ & 0.180 & $1.79 \pm 0.64$ & $2.14 \pm 0.49$ & 0.097 \\
\hline Lac & $5.26 \pm 4.48$ & $2.07 \pm 1.77$ & 0.040 & $4.45 \pm 3.17$ & $2.33 \pm 2.15$ & $0.034^{*}$ \\
\hline Ammonia & $169.44 \pm 60.73$ & $109.66 \pm 33.35$ & $0.010^{*}$ & $153.12 \pm 79.66$ & $67.44 \pm 26.42$ & $<0.001^{*}$ \\
\hline TNF-a & $107.01 \pm 41.78$ & $98.23 \pm 22.95$ & 0.548 & $107.00 \pm 31.35$ & $76.03 \pm 21.84$ & $0.003^{*}$ \\
\hline IL-6 & $86.75 \pm 29.14$ & $69.10 \pm 20.00$ & 0.113 & $81.64 \pm 23.85$ & $52.66 \pm 15.92$ & $<0.001^{*}$ \\
\hline
\end{tabular}

ALT alanine transaminase, $\mathrm{U} / \mathrm{L}, A S T$ aspartate aminotransferase, $\mathrm{U} / \mathrm{L}, \gamma$-GT $\gamma$-glutamyltransferase, $\mathrm{U} / \mathrm{L}, T B / L$ total bilirubin, $\mu \mathrm{mol} / \mathrm{L}, \mathrm{DB} / \mathrm{L}$ direct bilirubin, $\mu \mathrm{mol} / \mathrm{L}, T B A$ total bile acid, $\mu \mathrm{mol} / \mathrm{L}, A L P$ alkaline phosphatase, $\mathrm{U} / \mathrm{L}, P T$ prothrombin time, $\mathrm{s}, A P T T$ activated partial thromboplastin time, $\mathrm{s}$, INR international normalized ratio, Fib ferritin, $\mathrm{g} / \mathrm{L}$, Lac lactate, mmol/L; Ammonia, $\mu \mathrm{mol} / \mathrm{L}, T N F-a$ tumor necrosis factor a, pg/mL, IL-6 interleukin 6, pg/mL, T0: baseline before treatment, T72: $72 \mathrm{~h}$ after treatment ${ }^{*}$ indicates $P<0.05$ compared with TO

ratio of continuous hemofiltration therapy was significantly higher in survivors than in non-survivors $(78.6 \%$ vs. $38.5 \%, P<0.05)$. Among the indicators for liver function, the levels of TBIL in non-survivors were significantly higher than that in survivors $(232.99 \pm 88.49 \mu \mathrm{mol} / \mathrm{L}$ vs. $134.55 \pm 127.51 \mu \mathrm{mol} / \mathrm{L}, P<0.05$ ) (Table 3). There were increasing trend but without statistical differences in respect of the levels of ALT, $\gamma$-GT, DBIL, TBA, INR, Lac, ammonia, TNF- $\alpha$ and IL- 6 in non-survivors compared with survivors (all $P>0.05$, Table 3). Multivariate logistic regression analysis showed that continuous hemofiltration therapy (Odd ratio $[O R]: 0.091,95 \%$ confidence interval $[C I]: 0.009-0.948, P=0.045)$ and the level of TBIL (OR: 20.980, 95\% CI: 1.852-237.673, $P=0.014$ ), but not age (OR: $0.578,95 \% C I: 0.083-4.051, P=0.578$ ), were independent factors associated with 28-day mortality of patients with sepsis-associated liver dysfunction (Table 4). Furthermore, the continuous hemofiltration therapy and the levels of serum TBIL were significantly correlated with 28-day mortality of patients with bacterial sepsis complicated by liver dysfunction $(r=-0.408, P=0.035 ; r=0.42$, $P=0.029$, respectively).
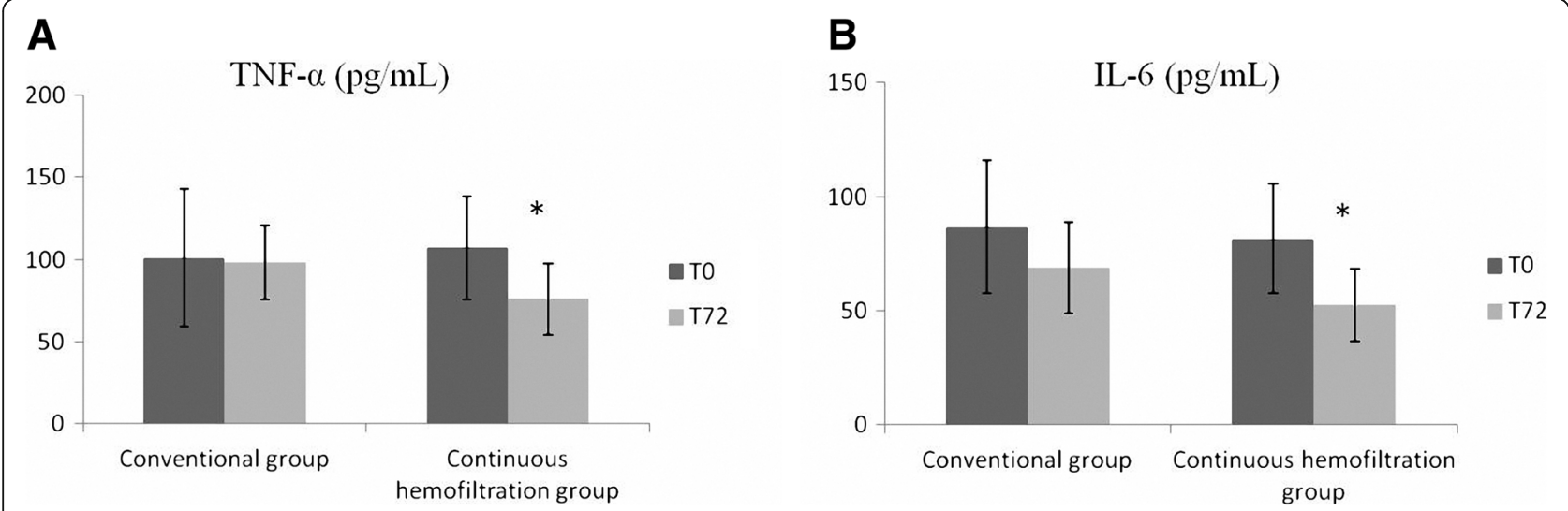

Fig. 2 Changes of the serum levels of TNF-a (a) and IL-6 (b) in patients with sepsis-associated liver dysfunction initially infected by bacteria after treatment with or without continuous hemofiltration. T0: baseline before treatment, T72: $72 \mathrm{~h}$ after treatment. * indicates $P<0.05$ compared with T0 
Table 3 Comparison of biochemical and clinical parameters between survivor and non-survivor with sepsis-associated liver dysfunction initially infected by bacteria enrolled in study

\begin{tabular}{|c|c|c|c|}
\hline Variables & Survivors $(n=14)$ & Non-survivors $(n=13)$ & P \\
\hline Cases with CRRT, n (\%) & $11(78.6 \%)$ & $5(38.5 \%)$ & $0.034^{*}$ \\
\hline Age, month, median (range) & $30(2-132)$ & $12(2-192)$ & 0.704 \\
\hline Male, n (\%) & $5(35.7 \%)$ & $8(61.5 \%)$ & 0.180 \\
\hline Stay in PICU, day, median (range) & $9.5(4-36)$ & $10(4-28)$ & 1.000 \\
\hline Body temperature, ${ }^{\circ} \mathrm{C}$ & $39(38-40)$ & $38.8(36-41)$ & 0.678 \\
\hline Hepatomegaly, n (\%) & $10(71.4 \%)$ & $6(46.2 \%)$ & 0.182 \\
\hline Hypoproteinemia, n (\%) & $9(64.3 \%)$ & $13(100 \%)$ & 0.083 \\
\hline $\begin{array}{l}\text { Pediatric Risk of Mortality III } \\
\text { (PRISM III), median (range) }\end{array}$ & $12.55(10-17)$ & $14.6(10-20)$ & 0.252 \\
\hline \multicolumn{4}{|l|}{ Co-organ dysfunction } \\
\hline ARDS, n (\%) & $9(64.3 \%)$ & $4(30.8 \%)$ & 0.082 \\
\hline Kidney injury, n (\%) & $5(35.7 \%)$ & $6(46.2 \%)$ & 0.581 \\
\hline Encephalopathy, n (\%) & $4(28.6 \%)$ & $6(46.2 \%)$ & 0.585 \\
\hline Shock, n (\%) & $5(35.7 \%)$ & $8(61.5 \%)$ & 0.180 \\
\hline \multicolumn{4}{|l|}{ Infection origin } \\
\hline Respiratory system, n (\%) & $8(57.1 \%)$ & $3(23.1 \%)$ & 0.072 \\
\hline Digestive system, n (\%) & $3(21.4 \%)$ & $4(30.8 \%)$ & 0.580 \\
\hline Urinary system, n (\%) & $2(14.3 \%)$ & $1(7.7 \%)$ & 0.586 \\
\hline Central nervous system, $\mathrm{n}(\%)$ & $1(7.1 \%)$ & $5(38.5 \%)$ & 0.050 \\
\hline \multicolumn{4}{|l|}{ Pathogens } \\
\hline Escherichia coli, $\mathrm{n}$ & $5(35.7 \%)$ & $5(38.5 \%)$ & 0.883 \\
\hline Pseudomonas aeruginosa, $\mathrm{n}$ & $4(28.6 \%)$ & $2(15.4 \%)$ & 0.406 \\
\hline Klebsiellapneumoniae, n & $1(7.1 \%)$ & $0(0 \%)$ & 1.000 \\
\hline Streptococcus pneumoniae, $\mathrm{n}$ & $4(28.6 \%)$ & $3(23.1 \%)$ & 0.744 \\
\hline Staphylococcus aureus, $\mathrm{n}$ & $0(0 \%)$ & $3(23.1 \%)$ & 0.172 \\
\hline \multicolumn{4}{|l|}{ Infection markers } \\
\hline WBC & $11.10 \pm 8.48$ & $12.96 \pm 6.43$ & 0.528 \\
\hline PCT & $5.71 \pm 3.64$ & $6.13 \pm 4.96$ & 0.805 \\
\hline CRP & $90.07 \pm 44.65$ & $106.92 \pm 61.66$ & 0.421 \\
\hline \multicolumn{4}{|l|}{ Liver function } \\
\hline ALT & $484.21 \pm 128.89$ & $643.94 \pm 303.62$ & 0.083 \\
\hline AST & $1059.50 \pm 848.05$ & $954.94 \pm 651.32$ & 0.724 \\
\hline$\gamma$-GT & $143.57 \pm 69.92$ & $205.46 \pm 144.19$ & 0.163 \\
\hline TBIL & $134.55 \pm 127.51$ & $232.99 \pm 88.49$ & $0.029^{*}$ \\
\hline DBIL & $108.89 \pm 88.00$ & $169.99 \pm 79.64$ & 0.071 \\
\hline TBA & $92.22 \pm 21.47$ & $111.93 \pm 31.51$ & 0.067 \\
\hline ALP & $166.43 \pm 33.24$ & $172.23 \pm 32.84$ & 0.653 \\
\hline PT & $20.56 \pm 6.47$ & $31.62 \pm 26.07$ & 0.136 \\
\hline APTT & $58.83 \pm 23.16$ & $66.46 \pm 33.73$ & 0.497 \\
\hline INR & $1.55 \pm 0.37$ & $2.41 \pm 1.94$ & 0.117 \\
\hline Fib & $1.51 \pm 0.73$ & $1.91 \pm 0.76$ & 0.171 \\
\hline Lac & $4.20 \pm 3.45$ & $5.50 \pm 3.99$ & 0.410 \\
\hline Ammonia & $139.07 \pm 62.24$ & $182.06 \pm 75.11$ & 0.122 \\
\hline TNF-a & $96.89 \pm 30.65$ & $117.89 \pm 37.66$ & 0.123 \\
\hline IL-6 & $75.78 \pm 21.75$ & $92.27 \pm 27.70$ & 0.096 \\
\hline
\end{tabular}

ALT alanine transaminase, $\mathrm{U} / \mathrm{L}, A S T$ aspartate aminotransferase, $\mathrm{U} / \mathrm{L}, \gamma$-GT $\gamma$-glutamyltransferase, $\mathrm{U} / \mathrm{L}, T B / L$ total bilirubin, $\mu \mathrm{mol} / \mathrm{L}, D B I L$ direct bilirubin, $\mu \mathrm{mol} / \mathrm{L}, T B A$ total bile acid, $\mu \mathrm{mol} / \mathrm{L}, A L P$ alkaline phosphatase, $\mathrm{U} / \mathrm{L}, P T$ prothrombin time, $\mathrm{s}, A P T T$ activated partial thromboplastin time, $\mathrm{s}, I N R$ international normalized ratio, Fib ferritin, $\mathrm{g} / \mathrm{L}$, Lac lactate, $\mathrm{mmol} / \mathrm{L}$; Ammonia, $\mu \mathrm{mol} / \mathrm{L}, T N F-a$ tumor necrosis factor a, $\mathrm{pg} / \mathrm{mL}$, IL-6 interleukin $6, \mathrm{pg} / \mathrm{mL}$

*indicates $P<0.05$ compared with survivors 
Table 4 Multivariate logistic regression analysis of independent factors associated with 28-day mortality of patients with sepsisassociated liver dysfunction initially infected by bacteria

\begin{tabular}{llll}
\hline Variables & $O R$ & $95 \% \mathrm{Cl}$ & $P$ \\
\hline Continuous hemofiltration & 0.091 & $0.009-0.948$ & 0.045 \\
TBIL & 20.980 & $1.852-237.673$ & 0.014 \\
Age & 0.578 & $0.083-4.051$ & 0.578 \\
\hline TBL
\end{tabular}

TBIL total bilirubin, OR odd ratio, $95 \% \mathrm{Cl} 95 \%$ confidence interval

\section{Discussion}

Continuous hemofiltration has been preferred as an effective adjuvant therapy for the treatment of systemic inflammatory syndromes in intensive care unit. In the present study, 28-day mortality of patients with bacterial sepsis-associated liver dysfunction was significantly reduced in the continuous hemofiltration group compared with the conventional management group, which was associated with decreasing the levels of TBIL, DBIL, TBA, Lac, TNF- $\alpha$ and IL- 6 after 72 h treatment. And continuous hemofiltration therapy, as a protective factor, was significantly correlated with 28-day mortality of patients with bacterial sepsis complicated by liver dysfunction. To our knowledge, it is the first study to assess the clinical effect of continuous hemofiltration on 28-day mortality of bacterial sepsis-associated liver dysfunction in pediatric population.

The conventional management for liver dysfunction caused by bacteria includes antibiotics and supportive therapy to improve the disturbed homeostasis [18]. Despite the advances in conventional management, 28-day mortality of bacterial sepsis-associated liver dysfunction was $72.7 \%$ in our PICU. Though continuous hemofiltration is preferred to be effective tool to improve hemodynamics and fluid balance, there is controversial about whether continuous hemofiltration improves the mortality of critically ill. Previous study indicated that continuous hemofiltration application can significantly lower the 28 -day mortality $(38 \% v s .71 \%, P=0.011)$ and in-hospital mortality $(62 \%$ vs. $86 \%, P=0.04)$ in patients with severe burns and acute kidney injury [19]. However, the 72-h early-initiated continuous hemofiltration treatment has no effect on the 28-day mortality in patients with septic-shock-induced acute respiratory distress syndrome (ARDS) without acute kidney injury [20]. Our previous study indicated that continuous hemofiltration improved the inflammatory biomarkers but no advantage in mortality in patients with secondary hemophagocytic syndrome [21]. However, it is intriguing that continuous hemofiltration application significantly improved the 28-day mortality of patients with bacterial sepsis-associated liver dysfunction in our present study. Importantly, continuous hemofiltration therapy, as an independent protective factor, was significantly correlated with the prognosis of patients with bacterial sepsis complicated by liver dysfunction. Consistently, Deep et al. [12] reported that patients with pediatric acute liver failure (PALF) treated with continuous hemofiltration had a significantly increased chance of survival based on retrospective analysis $(H R, 4 ; 95 \% C I, 1.5-11.6 ; P=$ 0.006). Otherwise, the survival rate of total 27 patients with bacterial sepsis-associated liver dysfunction was $51.85 \%(14 / 27)$ in our study. However, the survival rate of patient in continuous hemofiltration group was $68.7 \%$ in our study, which was similar to the $73.2 \%$ survival rate in patients with PALF in United states [22]. All these results indicated that continuous hemofiltration should be preferred effective adjuvant therapy to improve survival rate of patients with PALF and bacterial sepsis-associated liver dysfunction in children.

The timing to perform continuous hemofiltration is very important to improve the prognosis. The average interval time to initiate continuous hemofiltration after PICU admission was $(22.06 \pm 17.68)$ hours in our study. Consistently, Deep et al. reported that the average time to initiate continuous hemofiltration from PICU admission was $(27 \pm 6.9)$ hours [12]. Furthermore, we found that time to initiate continuous hemofiltration from PICU admission was significantly shorter in survivors compared with non-survivors, suggesting that the interval time between continuous hemofiltration initiation and PICU admission affects the outcome of bacterial sepsis-associated liver dysfunction. So, it is important to rapidly identify pathogen and indications for continuous hemofiltration initiation in patients with bacterial sepsis-associated liver dysfunction.

In the present study, continuous hemofiltration effectively decreased the levels of TBIL, DBIL, TBA, ammonia, Lac, TNF- $\alpha$ and IL-6. Our results are consistent with the report of previous study in acute liver failure before liver transplantation [21]. The levels of TBIL, DBIL, TBA, Lac, TNF- $\alpha$ and IL- 6 were significantly decreased after $72 \mathrm{~h}$ treatment in the continuous hemofiltration group (all $P<$ 0.05), other than in the conventional management group (all $P>0.05$, Table 2). According to the introduction for Gambro prisma filter, molecules with molecular weight < $50 \mathrm{kDa}$ could be wiped off. The bilirubin and lactate are "small" molecules, and TNF- $\alpha(\sim 17 \mathrm{kDa}-52 \mathrm{kDa}$ peptide which circulates as a trimer) and IL-6 $(\sim 21 \mathrm{kDa})$ are "large" molecules. Generally, the more a molecule weighs, the larger it is in size and the more resistant it is to transport. So, the changes of serum TBIL, DBIL, TBA, Lac levels could be results from directly wiping off. However, continuous hemofiltration might regulate liver function as an adjuvant therapy. So, we speculated that the changes of serum TNF- $\alpha$ and IL- 6 levels were contributed by both directly removing cytokines and indirectly regulating liver function. In addition, continuous hemofiltration can significantly improve the hemodynamic stability and 
neurological status in children with acute liver failure [23]. Whether hemodynamic stability and neurological status are influenced by continuous hemofiltration therapy in patients with bacterial sepsis-associated liver dysfunction should be investigated in the future.

Our study has some limitations. Firstly, this is a retrospective observational study with limited number of patients from a single center. This conclusion needs further study in prospective study with larger sample size. Secondly, some patients with severe coagulation disorders, or biofilm allergic reaction, or catheter difficult cannot perform continuous hemofiltration, although the patients were complicated with acute kidney injury, which would result in selection bias. Thirdly, we could not real-time monitor the changes of serum levels of TBIL, DBIL, TBA, Lac, ammonia, TNF- $\alpha$ and IL- 6 during the treatment. Nevertheless, our results are noteworthy because continuous hemofiltration significantly improves 28 -day mortality in pediatric patients with bacterial sepsis-associated liver dysfunction. More importantly, the present study brings an arousal of the potential benefits of continuous hemofiltration in pediatric patients with bacterial sepsis-associated liver dysfunction. It warrants further research using well-designed randomized controlled trials based on multi-site and larger simple size.

\section{Conclusions}

In conclusion, 28-day mortality of patients with bacterial sepsis-associated liver dysfunction was significantly improved in the continuous hemofiltration group, which was related to the decreased serum levels of TBIL, DBIL, TBA, Lac, ammonia, TNF- $\alpha$ and IL- 6 after $72 \mathrm{~h}$ treatment. Further larger simple size trial is needed to provide evidence on the role of continuous hemofiltration in bacterial sepsis-associated liver dysfunction.

\section{Additional file}

Additional file 1: No. of patients, age, BMI, length of PICU stay, Body temperature, PRISM III, group ("0" for conventional group, "1" for CRRT group), prognosis ("0" for survivor, "1" for non-survivor), No. of organ dysfunction, co-morbidities (jaundice, hepatomegaly, shock, encephalopathy, renal injury, Hypoproteinemia, ARDS, Primary liver disease), site of infection, pathogen, biochemical indexes (CRP, PCT, WBC, ALT, AST, $Y$-GT, TBIL, DBIL, TBA, ALP, PT, APTT, Fib, INR, Lac, Ammonia, TNF- $a$ and IL-6). The additional file includes the information about demographic and clinical characteristics of patients, group, co-morbidities, pathogen, and results of laboratory test before and after CRRT in patients with sepsis-associated liver dysfunction. (XLS 34 kb)

\section{Abbreviations}

ACT: Activated coagulation time; ALT: Alanine aminotransferase; APTT: Activated partial thromboplastin time; DBIL: Direct bilirubin; $\mathrm{G}^{-}$: Gramnegative; $G^{+}$: Gram-positive; IL-6: Interleukin - 6; INR: International normalized ratio; Lac: Lactate; LPS: Lipopolysaccharide; PICU: Pediatric intensive care unit; PRISM III: Pediatric Risk of Mortality III; PT: Prothrombin time; TBA: Total bile acids; TBIL: Total Bilirubin; TNF-a: Tumor necrosis factor- $\alpha$; $\gamma-G T$ : $\gamma$ glutamyltranspeptidase

\section{Acknowledgements}

We thank for the support from Science and Technology Commission of Shanghai Municipality (16411970300, 18411951000, 17411968900), Shanghai Municipal Education Commission-Gaofeng Clinical Medicine Grant support (DLY201618, 20171928), New Advanced Technology Project at the Shanghai City Hospital Development Center (SHDC12014116).

\section{Funding}

This study was supported by Science and Technology Commission of Shanghai Municipality (16411970300, 18411951000, 17411968900), Shanghai Municipal Education Commission-Gaofeng Clinical Medicine Grant support (DLY201618, 20171928), New Advanced Technology Project at the Shanghai City Hospital Development Center (SHDC12014116).

\section{Availability of data and materials}

Our present study was a retrospective observational study. All the data were obtained from medical records of patients. The raw data was submitted as Additional file 1.

\section{Authors' contributions}

Conceived and designed the study: CW and YZ. Collected and analyzed data: $X X, Y C, F W, Y R$. Contributed analysis tools and discussion: $X X, C W$ and $Y Z$. Wrote the paper: $X X, Y Z$ and CW. All authors read and approved the final manuscript.

\section{Ethics approval and consent to participate}

This study was approved by Ethical Committee of Children's Hospital Affiliated to Shanghai Jiao Tong University and conducted in accordance with provisions of the Declaration of Helsinki (Approval numbers: 2016 R011E02). The written informed consents were obtained from all patients' parents.

\section{Consent for publication}

Not applicable.

\section{Competing interests}

The authors declare that they have no competing interests.

\section{Publisher's Note}

Springer Nature remains neutral with regard to jurisdictional claims in published maps and institutional affiliations.

\section{Author details}

'Department of Critical Care Medicine, Shanghai Children's Hospital, Shanghai Jiao Tong University, No.355 Luding Road, Putuo District, Shanghai 200062, China. Institute of Pediatric Critical Care, Shanghai Jiao Tong University, No.355 Luding Road, Putuo District, Shanghai 200062, China.

Received: 12 December 2017 Accepted: 3 August 2018

Published online: 11 August 2018

\section{References}

1. Singer M, Deutschman CS, Seymour CW, Shankar-Hari M, Annane D, Bauer M, Bellomo R, Bernard GR, Chiche JD, Coopersmith CM, et al. The third international consensus definitions for sepsis and septic shock (Sepsis-3). JAMA. 2016:315(8):801-10.

2. Southeast Asia Infectious Disease Clinical Research N. Causes and outcomes of sepsis in Southeast Asia: a multinational multicentre cross-sectional study. Lancet Glob Health. 2017;5(2):e157-67.

3. Iwasaki A, Medzhitov R. Regulation of adaptive immunity by the innate immune system. Science. 2010;327(5963):291-5.

4. Schulte W, Bernhagen J, Bucala R. Cytokines in sepsis: potent immunoregulators and potential therapeutic targets--an updated view. Mediat Inflamm. 2013:2013:165974.

5. Dhainaut JF, Marin N, Mignon A, Vinsonneau C. Hepatic response to sepsis: interaction between coagulation and inflammatory processes. Crit Care Med. 2001;29(7 Suppl):S42-7.

6. Kothari N, Bogra J, Abbas H, Kohli M, Malik A, Kothari D, Srivastava S, Singh PK. Tumor necrosis factor gene polymorphism results in high TNF level in sepsis and septic shock. Cytokine. 2013;61(2):676-81.

7. Yan J, Li S, Li S. The role of the liver in sepsis. Int Rev Immunol. 2014;33(6): 498-510. 
8. Strnad P, Tacke F, Koch A, Trautwein C. Liver - guardian, modifier and target of sepsis. Nat Rev Gastroenterol Hepatol. 2016;14(1):55.

9. Boschee ED, Cave DA, Garros D, Lequier L, Granoski DA, Guerra GG, Ryerson $L M$. Indications and outcomes in children receiving renal replacement therapy in pediatric intensive care. J Crit Care. 2014;29(1):37-42.

10. Villa G, Neri M, Bellomo R, Cerda J, De Gaudio AR, De Rosa S, Garzotto F, Honore PM, Kellum J, Lorenzin A, et al. Nomenclature for renal replacement therapy and blood purification techniques in critically ill patients: practical applications. Crit Care. 2016;20(1):283.

11. Kade G, Lubas A, Rzeszotarska A, Korsak J, Niemczyk S. Effectiveness of high cut-off hemofilters in the removal of selected cytokines in patients during septic shock accompanied by acute kidney injury-preliminary study. Med Sci Monit. 2016;22:4338-44.

12. Deep A, Stewart CE, Dhawan A, Douiri A. Effect of continuous renal replacement therapy on outcome in pediatric acute liver failure. Crit Care Med. 2016;44(10): 1910-9.

13. Goldstein B, Giroir B, Randolph A, International Consensus Conference on Pediatric S. International pediatric sepsis consensus conference: definitions for sepsis and organ dysfunction in pediatrics. Pediatr Crit Care Med. 2005; 6(1):2-8.

14. Dellinger RP, Levy MM, Rhodes A, Annane D, Gerlach H, Opal SM, Sevransky JE, Sprung CL, Douglas IS, Jaeschke R, et al. Surviving sepsis campaign: international guidelines for management of severe sepsis and septic shock: 2012. Crit Care Med. 2013:41(2):580-637.

15. Miao H, Wang F, Xiong X, Wang C, Zhang Y. Clinical benefits of highvolume hemofiltration in critically ill pediatric patients with severe sepsis: a retrospective cohort study. Blood Purif. 2017;45(1-3):18-27.

16. Uchino S, Bellomo R, Morimatsu H, Morgera S, Schetz M, Tan I, Bouman C, Macedo E, Gibney N, Tolwani A, et al. Continuous renal replacement therapy: a worldwide practice survey. The beginning and ending supportive therapy for the kidney (B.E.S.T. kidney) investigators. Intensive Care Med. 2007;33(9):1563-70.

17. Hsu RK, McCulloch CE, Heung M, Saran R, Shahinian VB, Pavkov ME, Burrows NR, Powe NR, Hsu CY, Centers for Disease C, et al. Exploring potential reasons for the temporal trend in dialysis-requiring AKI in the United States. Clin J Am Soc Nephrol. 2016;11(1):14-20.

18. Chirico G, Cortinovis S, Fonte C, Giudici G. Bacterial sepsis. J Chemother. 2007;19(Suppl 2):28-30.

19. Chung KK, Lundy JB, Matson JR, Renz EM, White CE, King BT, Barillo DJ, Jones JA, Cancio LC, Blackbourne LH, et al. Continuous venovenous hemofiltration in severely burned patients with acute kidney injury: a cohort study. Crit Care. 2009;13(3):R62.

20. Meng JB, Lai ZZ, Xu XJ, Ji CL, Hu MH, Zhang G. Effects of early continuous venovenous hemofiltration on E-selectin, hemodynamic stability, and ventilatory function in patients with septic-shock-induced acute respiratory distress syndrome. Biomed Res Int. 2016;2016:7463130.

21. Cui Y, Zhang YC, Kang YL, Ren YQ, Miao HJ, Wang F. High-volume hemofiltration in critically ill patients with secondary hemophagocytic lymphohistiocytosis/macrophage activation syndrome: a prospective study in the PICU. Pediatr Crit Care Med. 2016;17(10):e437-43.

22. Kulkarni S, Perez C, Pichardo C, Castillo L, Gagnon M, Beck-Sague C, Gereige $\mathrm{R}$, Hernandez $\mathrm{E}$. Use of pediatric health information system database to study the trends in the incidence, management, etiology, and outcomes due to pediatric acute liver failure in the United States from 2008 to 2013. Pediatr Transplant. 2015;19(8):888-95.

23. Chevret L, Durand P, Lambert J, Essouri S, Balu L, Devictor D, Tissieres P. High-volume hemofiltration in children with acute liver failure*. Pediatr Crit Care Med. 2014;15(7):e300-5.

\section{Ready to submit your research? Choose BMC and benefit from}

- fast, convenient online submission

- thorough peer review by experienced researchers in your field

- rapid publication on acceptance

- support for research data, including large and complex data types

- gold Open Access which fosters wider collaboration and increased citations

- maximum visibility for your research: over $100 \mathrm{M}$ website views per year

At BMC, research is always in progress.

Learn more biomedcentral.com/submissions 